\title{
Alpha Fetoprotein and Hepatocellular Carcinoma: An Opinion
}

\author{
Dafina Nikolova* \\ University Clinic of Gastroenterohepatology, Skopje, Republic of Macedonia
}

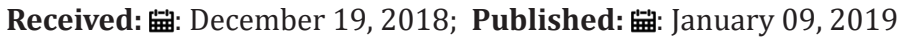

*Corresponding author: Dafina Nikolova, University Clinic of Gastroenterohepatology, Skopje, Republic of Macedonia

Keywords: Alpha fetoprotein; HCC; Blood Marker; Low AFP HCC

Abbreviations: HCC: Hepatocellular Carcinoma; AFP: Alpha Fetoprotein; DCP: Des-Gamma-Carboxy Prothrombin; GP: Golgi Protein; GEP: GranulinEpitelin Precursor; SCCA: Squamous Cell Carcinoma Antigen

\section{Opinion}

Hepatocellular carcinoma (HCC), an aggressive liver cancer, accounts about $90 \%$ of the primary liver carcinoma. It is a cancer with rising incidence in many countries in the past few decades and it is the third most common cause of cancer related mortality Worldwide. HCC is disease with short -term survival of the patients despite the recent development of the surgical techniques and other types of therapies. The survival is prolonged for patients with small and early diagnosed tumors. Therefore, early detection of HCC is extremely important for effective management [1]. HCC is inflammation related cancer and, in most patients, it occurs in cirrhotic liver. Considering the fact that HCC may have different clinical presentation, complicated with the symptoms of underlining inflammation and cirrhosis the clinician can be confused in selection of the most appropriate treatment of the patients with HCC. This condition leads to necessity of finding out the most useful markers for early diagnosis of the tumor $[1,2]$. The number of diagnosed asymptomatic patients with HCC increased in the few past decades due to the increased awareness of HCC rising incidence and due to the initiation of screening and surveillance of the patients belonging to the risk groups, using imaging methods, usually ultrasound and measuring the serum levels of Alpha fetoprotein (AFP) [2].

AFP is serum glycoprotein produced by fetal yolk sac and fetal liver tissue and it drops rapidly after the birth under $10 \mathrm{ng} / \mathrm{mL}$. HCC cells produce AFP and the serum level of AFP is usually increased in patients with HCC; therefore, AFP is the most used marker for detecting HCC. However elevated AFP is not specific for HCC and it can be elevated in patients with cirrhosis, chronic hepatitis, cancer of biliary tract, pancreas and stomach, testicle tumors, after liver resection, toxic injuries and during pregnancy [2,3]. It is considered that serum level of AFP $>400-500 \mathrm{ng} / \mathrm{mL}$ is diagnostic for HCC especially when corresponding to clinical symptoms and imaging findings. With serum level of 500ng/mL, AFP has a sensitivity of about $45 \%-50 \%$ and a specificity of more than $90 \%$ in revealing HCC in a patient with underlining liver disease [2-4]. Many authors reported AFP not only as a diagnostic marker for HCC but also as a prognostic marker which correlates with unfavorable prognostic factors [5], as a marker for disease relapse following liver transplantation [5], for monitoring patients after therapeutic treatment [6], tumor progression and survival [7]. Other authors have found that AFP had a low sensitivity in diagnosing HCC and low prognostic value [8].

With serum level $<400 \mathrm{ng} / \mathrm{mL}$ the specificity and sensitivity of AFP as a diagnosing marker decrease [3]. Therefore, some authors investigated AFP isoforms in order to improve its accuracy. Isoform AFP-L3 is found to be positive in about $35 \%$ of patients with small HCC, even smaller than $2 \mathrm{~cm}$. Fractions of AFP, bands III and IV are considered to be specific for HCC also, band II is shown to have better predictive value in comparison with conventional AFP, but none of them have been used in clinical practice [3]. However, there are patients with HCC who have normal or low level of serum AFP. According to some authors this group of patients accounts about $30 \%$ of all patients with HCC including those with advanced cancer [3], and according to others this group accounts up to 58\% [9]. So, another more sensitive blood mark is required in patients with HCC, especially in AFP negative patients or patients with 
low levels of AFP in the blood despite the coexisting tumor. Many other markers are investigated and suggested for detecting HCC especially these with normal or low AFP, including DCP (Desgamma-carboxy prothrombin), Glypican-3, SCCA1 (Squamous cell carcinoma antigen 1), GP73 (Golgi Protein 73), Osteopontin, GEP (Granulin-epitelin precursor), P-glycoprotein, enzymes different than DCP (Matrixmetaloproteinase, Glutamilsyntetase) isoenzymes and others.

It is not confirmed that any of them provide sufficient sensitivity and specificity [10-12]. So far efforts in discovering small HCC or HCC in early stage are not satisfactory and disappointing. Considering the fact that large size HCC may produce low serum level of AFP the issue becomes more complicated. In conclusion, early detection of HCC is extremely important for the patients affected by this cancer and AFP is not always useful blood biomarker. A huge number of patients with HCC and normal or low level of AFP urgently need a new blood marker with high specificity and sensitivity. It is also very important to continue research of low AFP HCC patients on AFP as well as other markers or to look for an effective combination of biomarkers, symptoms and imaging findings.

\section{References}

1. El Serag HB (2011) Hepatocellular Carcinoma. N Engl J Med 365: 11181127.

2. Cicalese L (2018) Hepatocellular carcinoma. Medscape.

3. Bialecki SE, Di Bisceglie MA (2005) Diagnosis of hepatocellular carcinoma. HPB (Oxford) 7(1): 26-34.

\section{ISSN: 2574-1241}

DOI: $10.26717 / B J S T R .2019 .12 .002316$

Dafina Nikolova. Biomed J Sci \& Tech Res

This work is licensed under Creative

Commons Attribution 4.0 License

Submission Link: https://biomedres.us/submit-manuscript.php
4. Johnson PJ (2001) The role of serum alpha-fetoprotein estimation in the diagnosis and management of hepatocellular carcinoma. Clin Liver Dis 5: $145-159$.

5. Görög D, Regöly Merei J, Paku S, Kopper L, Nagy P (2005) Alphafetoprotein expression is a potential prognostic marker in hepatocellular carcinoma. World J Gastroenterol 11(32): 5015-5018.

6. Schraiber L dos S, de Mattos AA, Zanotelli ML, Cantisani GP, Brandão $A B$, et al. (2016) Alpha-fetoprotein Level Predicts Recurrence After Transplantation in Hepatocellular Carcinoma. Medicine (Baltimore) 95(3): e2478.

7. Peng Li, Shan Shan Wang, Hui Liu, Ning Li, Michael A McNutt, et al. (2011) Elevated serum alpha fetoprotein levels promote pathological progression of hepatocellular carcinoma. World J Gastroenterol 17(41): $4563-4571$.

8. Farinati F, Marino D, De Giorgio M, Baldan A, Cantarini M, et al. (2006) Diagnostic and prognostic role of alpha-fetoprotein in hepatocellular carcinoma: both or neither? Am J Gastroenterol 101(3): 524-532.

9. Carr BI, Akkiz H, Üsküdar O, Yalçın K, Guerra V, et al. (2018) HCC with low- and normal-serum alpha-fetoprotein levels. Clin Pract (Lond) 15(1): 453-464.

10. Carr BI, Guerra V, Giannini EG, Farinati F, Ciccarese F, et al. (2014) Low alpha-fetoprotein HCC and the role of GGTP. Int J Biol Markers 29(4): 395-402.

11. AlSalloom AAM (2016) An update of biochemical markers of hepatocellular carcinoma. Int J Health Sci (Qassim) 10(1): 121-136.

12. Plentz RR, Malek NP (2015) Early Detection of Hepatocellular Carcinoma: How to Screen and Follow up Patients with Liver Cirrhosis According to the GERMAN S3 Guideline? Diagnostics (Basel). Dec 5(4): 497-503.

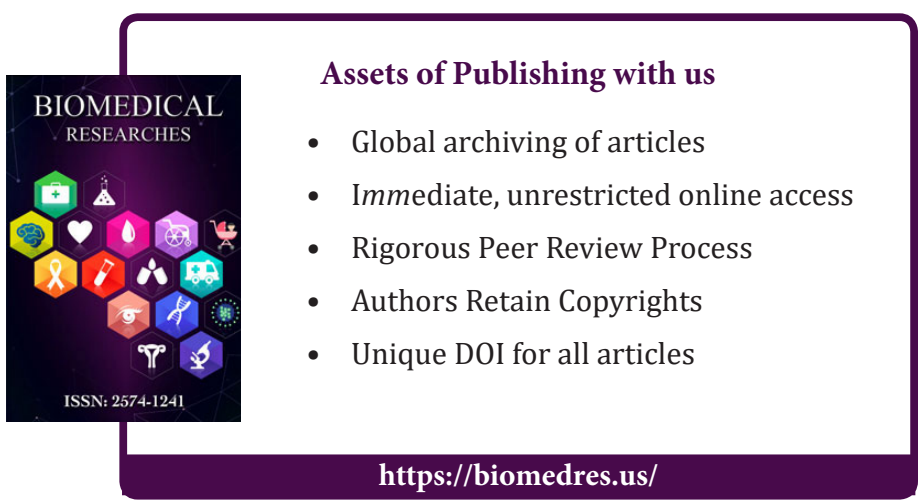

